\title{
Host Agency Perspectives on Facilitating Community- Based Clinical Experiences for Nursing Students
}

Sheryl Reimer-Kirkham

Trinity Western University, sheryl.kirkham@twu.ca

Landa Terblanche

Trinity Western University, landa.terblanche@twu.ca

Richard Sawatzky

Trinity Western University, rick.sawatzky@twu.ca

Catherine Hoe Eriksen

Trinity Western University, Catherine.HoeEriksen@twu.ca

Follow this and additional works at: https://qane-afi.casn.ca/journal

Part of the Medical Education Commons, and the Nursing Commons

\section{Recommended Citation}

Reimer-Kirkham, Sheryl; Terblanche, Landa; Sawatzky, Richard; and Hoe Eriksen, Catherine (2016) "Host Agency Perspectives on Facilitating Community-Based Clinical Experiences for Nursing Students," Quality Advancement in Nursing Education - Avancées en formation infirmière: Vol. 2: Iss. 1, Article 3.

DOI: https://doi.org/10.17483/2368-6669.1048

This Article is brought to you for free and open access by Quality Advancement in Nursing Education - Avancées en formation infirmière. It has been accepted for inclusion in Quality Advancement in Nursing Education - Avancées en formation infirmière by an authorized editor of Quality Advancement in Nursing Education - Avancées en formation infirmière. 
Host Agency Perspectives on Facilitating Community-Based Clinical Experiences for Nursing Students

\section{Cover Page Footnote}

We are grateful to the participants who contributed to the study. 


\section{Introduction}

Nursing education has moved beyond its traditional reliance on student experiences within hospitals and public health units to incorporate clinical placements in a broad range of alternative settings. Whether motivated by need for increased capacity, a broadened emphasis on health promotion and disease prevention, or philosophical goals of service learning, the increasing dependence upon student placements within alternative or innovative clinical placements has changed nursing education over the past twenty years (Hall, 2006; Hoe Harwood, Reimer-Kirkham, Sawatzky, Terblanche, \& Van Hofwegen, 2009; Reimer-Kirkham, Van Hofwegen, \& Hoe Harwood, 2005; Peters, Halcomb, \& McInnes, 2013). Leurer et al. (2011) observe the following:

The increased use of innovative clinical placements (ICPs) in the community creates opportunities for nursing students to practice broader health promotion strategies, such as strengthening community action and supporting the development of healthy public policies, as part of their education program. (p. 1)

Growing bodies of literature commend partnering with community-based agencies, some of which are non-health sector and may not employ registered nurses (Cohen \& Gregory, 2009; Pijl-Zieber, 2015; Van Doren \& Vander Werf, 2012), as the way forward through the clinical placement capacity challenge. A national survey noted that $96 \%$ of respondent Canadian baccalaureate nursing programs placed students in alternative community-based clinical placements for some component of their assigned clinical hours (Hoe Harwood et al., 2009). The survey reported that Canadian nurse educators rely upon student placements such as correctional facilities, Aboriginal communities, international placements, rural and parish settings; reports that are corroborated in other regions (Sloan, Keely, \& Groves, 2008; Stewart, 2007). Student learning in these community-based settings has been described as transformative, with students gaining enhanced critical thinking competencies (Pijl-Zieber \& Kalischuk, 2011; ReimerKirkham et al., 2005; Reimer-Kirkham, Van Hofwegen, \& Pankratz, 2009). Despite this widespread reliance on alternative placements and the reports of transformative learning, few studies have reported the host agency perspective. This project responded to this gap with the purpose of eliciting from host agencies their perspectives regarding innovative clinical placements.

\section{Background}

The project commenced with a literature review to ascertain published perspectives of community-based agencies related to hosting student nurse placements. Articles were retrieved by searching for English language literature published between 2004 and 2014 in CINAHL and PubMED electronic databases. Literature from nursing professional associations, including the Canadian Association Schools of Nursing (2014) and the National League for Nursing, was also reviewed. The literature review was complicated by a lack of consistency regarding terminology describing such student placements; we used search terms such as alternative, non-traditional, innovative, community, or non-health sector sites. Although many authors provided a discussion of non-hospital or community clinical placements, very few commented on host agencies' perspectives, particularly those in community agencies. The extensive literature review exercise yielded three conclusions: (a) there exists little published research on host agency perspectivesrather, nurse educator perspectives are reported; (b) discussions about host agency perspectives are embedded or peripheral in articles that discuss broader topics; and (c) database subject 
headings are generally inadequate to locate these articles, thus necessitating a manual, labourintensive, and potentially less reliable approach to locating relevant articles.

Collaboration between the practice and academia is seen as critical for the preparation of the public health nursing workforce (Keller, Schaffer, Schoon, Brueshoff, \& Jost, 2011). Peters et al. (2013) went further, stating that the relationship between the university and agency impacts the quality of the clinical placement. They explain that

factors that impact on the quality of the environment include the capacity of the facility to support the student placement and liaison between the health care organization that provide the clinical experience and the higher education institutions who deliver the baccalaureate programs. (p. 187)

Reflecting the importance of such relationships is a growing body of literature on universityagency partnerships, including sources related to service learning, although these are typically written from the perspective of nurse educators or students. In partnerships, nursing education programs collaborate with clinical agencies and the community to meet the health care needs of the community (Gaberson, Oermann, \& Shellenbarger, 2015). Many scholars have described the intentional negotiations required to achieve partnerships with community agencies (Henderson, Heel, \& Twentyman, 2007; Leurer et al., 2011). In their analysis of 'The Partners in Caring' model, Bernal, Shellman, and Reid (2004) highlighted three essential elements of successful university-agency partnerships as (a) dedication from both university and agency to develop partnerships that work and are sustainable (b) shared responsibility and commitment to care, and (c) open, effective communication. Hogard, Ellis, Ellis, and Barker (2005) echoed this emphasis on open communication; their summary of an audit conducted using the Hogard-Barker Communication Audit of Practice tool revealed high levels of dissatisfaction with the amount and quality of communication between agencies and universities. Peters et al. (2013) also concluded that agency staff desire greater consultation in the organization of clinical placements. Some academic-agency partnerships are becoming remarkably complex, exemplified by large health care entities, such as regional Health Authorities ${ }^{1}$ that encompass hundreds of clinical units and agencies, in partnership with multiple health care educational programs and institutions. This complexity can, according to Peters et al. (2013), lead to a distance between universities and agencies that can be interpreted as a lack of support from the university.

Despite such complexities and the efforts required to negotiate and maintain academicagency partnerships, many benefits are reported in the literature. Stallwood and Groh (2011) concluded change occurs in both the recipient and provider of service as a result of the service activity. Ganley et al. (2004) and Halcomb, Peters, and McInnes (2012) described that community agencies benefit from such partnerships; public health nurses were able to develop their skills as mentors and evaluators, research was more easily conducted, and client health status could be improved. Stewart (2007) observed benefits to agency staff such as having their knowledge updated through interactions with students, being able to focus more on strenuous issues, or attend career development workshops. Gaberson et al. (2015) described the benefits to the community as having control over the service provided and the recipients of service becoming better able to serve themselves and be served by their own actions. In a project that involved nursing students conducting home visits with people with chronic life-limiting

\footnotetext{
${ }^{1}$ In the western Canadian province which was the site of this study, the province's publicly-administered and funded health care services are delivered by seven regional Health Authorities.
} 
conditions, clients reported they learnt from the students and benefited from their visits (Pesut et al., 2015). Benefits to students included the development of skills in communication, critical thinking, and collaboration. Students are also reported as gaining a community perspective and commitment to health promotion in the community, and an awareness of diversity and cultural dynamics (Keller et al., 2011; Pijl-Zieber \& Kalischuk, 2011). Plowfield, Wheeler, and Raymond (2005) and Leurer et al. (2011) described benefits for students that included the opportunity to identify new health care needs, attend to more complex client needs, and opportunities to practice broader health promotion strategies.

Along with these reported benefits to agencies and students, challenges that agencies experienced through hosting undergraduate nursing students have also been identified. Kenyon and Peckover's (2008) analysis of community nurse and health visitor perspectives noted that community organizations were disrupted, fewer clients could be helped, some staff experienced professional anxieties when being shadowed by students, and already limited resources were further strained. Pijl-Zieber and Kalischuk (2011) described challenges for students as having difficulties to transition between caring for patients with health challenges to a more broad application of population health concepts. Pijl-Zieber (2015) went further to state that students might view the experiences in a non-traditional clinical placement as "second rate" since they might not be able to develop their specialized nursing knowledge and skills while allocated to these facilities.

While these benefits and challenges provide some indication of community agency perspectives on hosting undergraduate nursing students, focused investigation in relation to enhancing student placement capacity and ensuring optimal learning experiences is needed in order to assure a comprehensive understanding of the perspectives of host agencies. Given the extent to which nursing education programs rely on clinical placements, there is a need to pay serious attention to the perspectives of host agencies.

\section{Describing the Study}

The purpose of this project was to gain information from host agencies regarding innovative clinical placements. We specifically sought to gain insight into (a) how communitybased host agencies decide to host students, including how the number of students hosted is determined; (b) the nature of agency-university partnerships; and (c) the agency's experiences of hosting students in relation to benefits and issues that accompany hosting students.

This qualitative study employed the method of interpretive description (Thorne, 2008). A questionnaire with open-ended questions was designed based on themes derived from the literature review and earlier studies (a qualitative study and a national survey) eliciting information from students and educators regarding innovative clinical placements (Hoe Harwood et al., 2009; Reimer-Kirkham et al., 2005; Reimer-Kirkham et al., 2009). Questions included: "How do you decide whether to take student placements?"; "Are there benefits to hosting undergraduate nursing students? Please describe"; "How have students assisted with meeting the mandate of your agency?" and "Please comment on any challenges with these placements". The project received research ethics board approval from the researchers' university and participant rights were preserved through informed consent, by removing identifying information, and storing data under restricted access with availability only to the research team. Some of the researchers knew the participants from their work in organizing the clinical placements, but these researchers did not conduct the interviews and only viewed de-identified data. 
Administrators from twenty-five community-based agencies that hosted undergraduate nursing students from the researchers' university were invited to participate, with a final sample size of eighteen respondents who represented community-based agencies. Most of these administrators were nurses and most of the agencies were affiliated at least to some degree with the health care system (i.e., they were not non-health sector agencies). Nonetheless, we considered them as providing "innovative" or "alternative" clinical experiences in that most of these agencies operated relatively independently from the regional health authority (e.g., the host agency staff were not employees of the government-funded health authority). These agencies had provided placements for students in senior-level community health (e.g., at health centres in aboriginal communities and a university wellness centre) and mental health nursing courses (e.g., mental health clinics, group homes for people suffering from mental illness, rehabilitation centres) during the prior year. Researchers contacted participants initially by email and then with a telephone follow-up; this proved to be an effective recruitment strategy. Each participant was given the option of a telephone interview but most elected to complete the online survey because of its flexibility; five participants were interviewed on the phone by the researchers and 13 completed the open-ended survey questions online. Although the online survey proved convenient and economical, the quality of data (e.g., descriptiveness, detail) was considerably better with the telephone interview, which allowed for clarifying questions and prompts. Later interviews allowed us to validate the emerging analytic structure. Telephone interviews were recorded and transcribed.

Analysis of data was facilitated by qualitative data analysis software ( $\mathrm{NVivo}^{\mathrm{TM}}$ ). A preliminary code book was developed based on research questions and was informed by themes drawn from previous phases of the research program ((Hoe Harwood et al., 2009; ReimerKirkham et al., 2005).), and was refined as line-by-line coding progressed. Data analysis progressed through increasing levels of abstraction to the final themes presented below. The data were coded by a research assistant and reviewed by the research team, which contributed to rigour.

\section{Findings: Perspectives of Host Agencies}

The findings yielded insight into the perspectives of community agencies that host

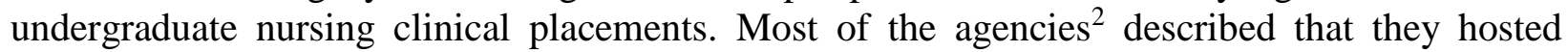
student placements from one or more nursing programs and in some cases other health care discipline programs, in addition to those from the researchers' university. We were struck by the eagerness of host agencies to participate in the study, suggesting that creating more opportunities to "hear" their perspectives was a worthwhile endeavor.

\section{Question \#1: Deciding to Host Students}

Participants were asked how they decided whether and how many students to host, and what factors influenced these decisions. Few of the respondents reported clearly set guidelines applied to the decision to host students. More often they seemed to make an "in the moment" decision (what one respondent referred to as "ad hoc") that depended on the interplay of various explicit and implicit factors.

\footnotetext{
${ }^{2}$ The various people (e.g., roles, professional training) who served as contact person at the agencies produced a challenge regarding capturing an agency perspective through a single spokesperson. While recognizing that it is administrators who speak on behalf of their respective agencies and each reflect not only their own experience, but also the collective response for agency staff, for brevity we refer to each "agency" as an entity.
} 
For the most part, the decision to host students was framed as a matter of agency capacity that was linked to staff availability and willingness to work with students. Several references were made to workload - "Workload is key" - with the inference that student placements added to workload. As one stated, "If we are short staffed, it is unlikely that we would accept a student". Another participant said the decision to host students depended on "whether my schedule allows time to do so"; another said: "Any time that I give to student placement takes away from my time as a clinician". The size of the agency factored into the decision, as aptly reflected in the comment, "space to put physical bodies". Another participant put it as: "we have two desks, nobody wants to be tripping over each other. You'd like to have a place where you can go apart. I mean staff might not want to be shadowed by a student all the time". There was also consideration of how the student(s) might contribute to the agency, whether through direct patient care or by completing a project for the agency. For larger agencies, requests from multiple institutions meant complicated decisions, as they strove to be "fair".

The decision to host students was also influenced by implied expectations felt by participants to accommodate ongoing student placements stemming from their personal philosophical views and professional commitments to student learning, or a health region mandate to provide for clinical education. One participant explained: "it is part of my own personal ethic to assist with learning".

Some commented that prior experiences with a particular nursing program, which might have related to specific students, clinical supervisors or program faculty, or dimensions of the university-agency partnerships, directly impacted their decision as to whether their agency would host students from that institution again. One participant stated, "[School X] has always sent excellent placements to us," and another disclosed, "I have... turned some agencies down that previously haven't been a positive experience". In summary, deciding to host students was influenced by various factors, some concrete and objective, others more obscure and subjective.

\section{Question \#2: Nature of Agency-University Partnerships}

Although a signed agreement was in place between the university and each of the agencies, the participants varied in their views on the nature of agency-university partnerships. The respondents were asked whether they recommended formal partnerships. In the case of a partnership involving a specific unit within a larger agency, the point was made that the partnership needed to be at the local and regional level, with the individual unit actively engaged, as reflected in the comment, "partnerships need to be built at a level beyond the local offices, but should not preclude local relationships". One participant noted that partnerships could expand capacity for placements: "a more coordinated approach will allow more sites to receive students, especially in rural areas".

Interestingly, several respondents indicated they did not think formal partnerships were necessary, with comments such as "I don't think it is necessary". A participant observed that a formal partnership would not really change proceedings, other than "setting up yet another committee". There was a perceived flexibility to more informal arrangements. One participant commented: "The informal aspect would be the freedom to be fluid in the number of students that are placed due to the ever evolving work within my role". Along with the flexibility was the matter of agency autonomy, with one participant stating: "I would need more information on what that would entail; what kind of commitment and responsibilities would be expected. I would 
need to look at what was proposed and, in consultation with my staff and director, decide if that would work for us".

Many participants described specific strategies they perceived could increase agency satisfaction with the hosting process. The opportunity for improved communication between all parties was a high priority, based on comments relating to participants seeking more reciprocal discussions and increased and timely feedback from the nursing programs about student placements. Agency-perceived need for increased and improved communication with clinical instructors and their more direct supervision of student placements was a theme among respondents. One participant described, "there's been some practicums when ...the students are placed here and we...never, ever hear from an instructor". Another participant elaborated the need for increased instructor presence and support of agency staff. With a formal partnership in place, one participant expected that clinical instructors would be better prepared, by knowing the "form and function of our place, and how we operate". Participants expressed a desire for more student feedback about how they felt the placement was beneficial to their learning and what improvements the agency could make for future students. One participant reported that she did not know how to refine the student experience because "[she hasn't] received actual feedback from a student's perspective as to if they feel they're gaining... an experience that they feel is necessary or that they could use". Overall, the picture of university-agency partnerships was varied, with preferences for and against formalized partnerships. Across these opinions was consistency in valuing involvement, flexibility, and communication between the nursing program and the host agency.

\section{Question \#3: Perspectives on "Hosting" Students-Benefits and Challenges}

The benefits of hosting undergraduate student nurses were described as outweighing the issues and challenges. Every participant noted that students brought "current" professional knowledge to their agency, which was considered a benefit, although this was balanced by some comments that students' lack of life experience, maturity, or knowledge about their agency's specific priorities and client needs could be an impediment. Agency staff members valued the professional nursing information students hold and that their questions challenged staff and required them to "keep [on] their toes". Hosting students was considered to increase staff morale, dedication and motivation as it "develop(ed) leadership and education skills", pressed staff to be continual learners, and to evaluate how their agency was applying the latest knowledge to client care. All participants affirmed that students provided helpful contributions to their agency's client care mandate. Two participants said students acted as additional "[sets] of eyes and ears", and others appreciated their dedication to spending time with clients who would otherwise not receive as much attention. Participants elaborated that hosting students promoted attaining agency outcomes such as recruitment, accreditation, and increasing visibility of the agency in the community. Another benefit mentioned was that students developed specifically targeted resources to increase the efficiency and quality of the agency's client care delivery.

Participants were also asked about challenges that might arise. In some situations, student presence was described as potentially having a negative effect in relation to care provision. One participant described that at their agency some clients were not always willing to have students participate in their care, while another noted that client care was sometimes hindered by students' presence; "community members are reluctant to seek my assistance as they feel I am already too busy". Hosting students required time and attention, and some participants expressed concern that this diminished their own effectiveness with clients and added to the staff workload. 
As one participant explained, "My role is very busy and finding the time to set aside for the students can present challenges; anytime that I give to student placements takes away from my time as a clinician". Students' limited placement hours (such as one 6- or 8-hour shift/week) was described as hindering students from forming beneficial relationships with clients and from gaining a comprehensive perspective of agency services. One participant stated, "there is a trust issue with our clients... and when [students] are only here one day a week, it's just really hard for them to connect".

Student professionalism and experience also contributed to perceptions as to whether student placements were deemed of help or hindrance. Students' appearance and dress, tardiness, and engagement all reflected perceived professionalism. One participant described working with a student who "was disinterested, bored, yawned most of the time, came late, [and] did not complete tasks given to her" such that the participant questioned the student's commitment to the placement. Lack of experience and knowledge was raised more frequently by respondents representing mental health agencies, likely representing the specialized knowledge required of mental health nurses. A student at one such agency "was not able to participate extensively in direct clinical work...given her lack of related experience". Another participant discussed the effects of this inexperience, explaining that students "put more emphasis on health and safety without completely thinking about what the person may want". Another respondent observed that at times students felt they were not being useful if all they were doing was talking with clients:

The best thing they can do is sit in the living room and talk to the client. A lot of our clients come here because they're lonely or depressed. And so just engaging with them is the most important thing a nursing student here can do. But I've had students just say, 'is there something else I can be doing? I don't feel like I'm doing anything.' It becomes a challenge for the student.

In some of the mental health settings, the students' youth, immaturity, and lack of life experiences were also reported as being problematic in the area of nurse-client boundaries, with some students sharing personal details on the one hand, or on the other hand, hesitating to form any kind of professional relationships with clients because the clients were at a psychiatric agency.

In response to a question regarding legal issues, all participants reported they had not encountered any such concerns related to hosting student nurses. A few participants described hypothetical situations that could arise, such as bureaucratic challenges in obtaining of agency required police or criminal record checks for international students. Likewise, ethical issues surrounding hosting of student placements were also not of great concern to respondents. Only three participants commented in response to the survey question regarding potential ethical issues and these responses were again qualified as potential rather than actual issues. The matter of student safety was raised as an ethical concern; one participant wondered if it was ethical to leave a student unattended with clients in that setting (identified as a maximum security correctional facility). The importance of client confidentiality was noted by a second respondent. A third participant noted that students needed to "put aside" their own moral values where they disagreed with clients' behaviours at that psychiatric agency.

In summary, agency personnel were generally positive about hosting nursing student placements and identified many benefits to the experience. Various actual or hypothetical issues that could arise were noted as challenges. Decisions about hosting student placements and the 
number of students accepted were based primarily on perceived agency benefits, staff availability and physical space, although having a negative experience with a student could result in declining placements altogether. While many did not see the need to formalize agencyuniversity partnerships, participants identified communication and instructor presence as two important factors contributing to positive host experiences.

\section{Discussion}

This qualitative study provides insights in relation to capacity, partnerships, and the implicit priority for the clinical placement itself. Each of these themes can be better understood when viewed through an overarching lens of the complexity which is characteristic of nursing practice today, particularly in alternative practice settings.

\section{Capacity to Host Students}

A matter for further study highlighted by this project is that of capacity. Determining and managing capacity is multi-dimensional and varied (Murray \& Williamson, 2009). Halcomb et al. (2012) reported nurse participants working in specialized areas in their study stated the need to "get students in" to enhance the future of their specialty. Participants in a study by Peters et al. (2013) stated inappropriate numbers of students were allocated on various occasions to their agencies and this "proved to be overly burdensome for them" (p. 188). The participants added further they would like to have more influence over the model of clinical placement. In some jurisdictions, audit tools have been developed to compare capacity and actual number of students. Clarke, Gibb, and Ramprogus (2003) found, in their study in the UK, that even when the Trusts were at maximum capacity for student nurse placements, they were using just $80 \%$ of their total audited capacity. However, most often other health professions students were sharing sites, and thus the sites could well be over audited capacity. In our study, there was not a consistent pattern of how placement decisions were made. Yet, the matter of who determines capacity and on what grounds decisions are made is vital to clinical placements in nontraditional, community-based settings. A database [HSPNet ${ }^{\mathrm{TM}}$ ] is used widely in Canada to provide electronic support to coordinate clinical placements in hospitals (acute care settings) for the majority of health professions programs. While invaluable to managing placements, the system itself does not determine capacity, and neither are most community-based agencies (other than public health units) part of HSPNet ${ }^{\mathrm{TM}}$. However, most often other health professions students were sharing sites, and thus the sites could well be over audited capacity. Hosting students from more than one educational facility was a dynamic that factored into decisions of capacity for the agencies in our study. Mechanisms such as electronic databases and audit tools to determine capacity for clinical placements merit further study.

Participants in our study used the language of "staff availability" as reason to decline student placements yet it was not clear how availability was determined or how the presence of students contributed to added workload. The comments about added workload are ambiguous considering that all participants affirmed the helpful contributions students made to client care. Future studies should seek to clarify this apparent contradiction where students represent added workload, and at the same time assist with client care. It may be that the various dimensions of workload factor into the perception of students increasing workload. Halcomb et al. (2012) conducted a study to explore the experiences of nurses when supervising undergraduate nursing students in a community setting. Participants stated that despite the additional time and multiple challenges involved when supervising nursing students, they were committed to providing the 
students with quality clinical learning experiences. While students could be assisting with patient care, in the overall balance they might still be adding to workload if they require a lot of supervision. Findings reported by Peters et al. (2013) included students were ill prepared as they lacked foundational knowledge related to the specific agency. Conversely, if students require less supervision, their contributions to client care would more likely be perceived as decreasing workload overall. Or, by another scenario, if students contributed significantly to non-patient care activities by, for example, completing projects of value to the agency, this too could leave an overall balance of lessening workload. Understanding the dynamics of staff availability and workload is increasingly important as capacity for placements continues to be of shared concern to nurse educators and health care agencies. For all participants, the decision to host students was characterized as a complex one that involved balancing a range of considerations relating to the educational institute and its students and the agency (and their clientele and staff), and one that might fluctuate from year to year depending on other circumstances and require creative problem-solving. When viewed through the lens of complexity theories, these considerations and adaptations are not considered as roadblocks but rather as innate or expected in an adaptive system (Rosenau, Watson, Vye-Rogers, \& Dobbs, 2015).

\section{Partnerships}

While much academic discourse at the university level emphasizes the development of partnerships, for agency respondents in our study, there were varied opinions expressed as to the importance or necessity of formal partnerships. The caution expressed by some agency personnel raises questions about whether partnerships might be more beneficial to the university than to the agency. This discrepancy then raises questions for future study: What does the word "partnership" mean to the stakeholders? In what circumstances are partnerships mutually beneficial? From the agency perspective, do partnerships facilitate increased capacity in any significant way? There was some suggestion in this study that partnerships could expand capacity for clinical placements, a finding shared by Barnett et al. (2008). In their Australian study, implementation of a collaborative learning model resulted in major increase $(58 \%)$ in the number of students placed. The successful model entailed eight attributes: leadership and commitment to collaboration from all major stakeholders; philosophy of learning community and interprofessional education opportunities; a common, supported, and rewarded preceptorship program; a dedicated clinical facilitator; greater use of different shifts and weekends for placements; a shared clinical calendar and expanded number of placement weeks; common clinical objectives, skill set and student evaluation tool; and regular face-to-face communication between key stakeholders. Several of these attributes were valued by participants in our study, including more communication with the nursing program and more visibility of clinical instructors. Several of the sites in our study hosted students from other health-related fields other than nursing, but little reference was made to the opportunity for interprofessional education. Applying Barnett et al.'s (2008) model and drawing on other research supporting interprofessional education (Hood, Leech, Cant, Gilbee, \& Baulch, 2014), we anticipate that attention to shared learning might further contribute to student placement capacity, including in intersectoral contexts.

Leurer et al. (2011) reported on focus groups held to explore the characteristics of quality community health placements; the focus group participants articulated a strong need for community-academic partnerships in terms of formalized agreements and clearly roles and expectations. Participants in our study also emphasized how they benefitted from the knowledge 
students brought to the community agencies, suggesting that a philosophy of a learning community of staff and students could provide another perspective on capacity-that of enhancing the clinical capacity of the staff.

\section{Benefits and Challenges}

Issues of incongruity between agency and university expectations became visible in our study. In the study conducted by Peters et al. (2013), participants felt uncertain of their role in facilitating the clinical placement. Most of these participants perceived the absence of the university involvement as a lack of support to them. In our study, whereas nursing programs tended to conceptualize or seek an "ideal placement", host agencies put more emphasis on the "ideal student". Both parties, in fact, may hold idealized expectations that may influence educational outcomes. Such mismatched ideals may result in host agencies "holding out" for the ideal student and hence reducing placement capacity, while educational institutions may disregard the importance of creating a good match between agency and student in their assumption that a "good placement" will provide a good learning experience for any student. The findings of this study suggest, then, that the assumptions carried by nursing programs regarding clinical placements may not necessarily be shared by host agencies. Further study is needed to substantiate this finding and to elicit in more detail the perspectives of host agencies. Although not interviewing host agency administrators, Pijl-Zieber, Barton, Awosoga, and Konkin (2015) also found disconnects between the views of stakeholders in education (students, faculty) and those in practice (nurses) in non-traditional community health placements. Faculty were more likely to carry an abstract, idealized orientation to learning, compared to students' preference for concrete, pragmatic learning and nurses' orientation to integrated learning. They concluded that such disconnects could adversely affect student learning outcomes. In our study, while different expectations and challenges were noted, these were not reported by the host agency administrators as a threat to students' learning. Different expectations between service and educational sectors have been identified by other authors, such as the discourses of practicereadiness where the service sector expects graduates to "hit the ground running" while the education sector holds such expectations as unrealistic given the complexity of today's health care services (Peters et al., 2013; Wolff, Pesut, \& Regan, 2010). Referencing this complexity, scholars have argued that learning in complex situations can build not just competence, but also capability with the ability to adapt to change, generate new knowledge, and continuously improve performance (Cooper \& Geyer, 2008; Fraser \& Greenhalgh, 2001). Peters et al. (2013) concluded in their study "enhanced communication and consultative processes between practice nurses and the universities will lead to more positive outcomes for all stakeholders" (p. 190). These discrepancies highlight the importance of learning the perspectives of educational partners and collaborators.

\section{Limitations}

Generalizability of study findings is limited by the size of the sample, and the lack of representativeness given only one geographic region and one educational institution were included. The study was conducted over a period of several years, with the majority of the data collected in 2008. 


\section{Concluding Comments}

Nurse educators have developed many innovations for nursing education in response to the current shortage of clinical placements. Nursing programs are increasingly relying on placements in community-based agencies (some of which are not health agencies), and university-agency collaborations are being developed to enhance capacity for student placements. Our interest was to elicit the perspectives of host agencies in these alternate sites regarding hosting undergraduate student clinical placements. The study revealed incongruities between the perspectives of these host agencies and typically held views of nursing programs, underlining the need for research in this area to generate knowledge about expanding capacity for clinical placements, enhancing partnerships, and enriching student learning outcomes. 


\section{References}

Barnett, T., Cross, M., Jacob, E., Shahwan-Akl, L., Welch, A., Caldwell, A., \& Berry, R. (2008). Building capacity for the clinical placement of nursing students. Collegian, 15(2), 55-61. http://dx.doi.org/10.1016/j.colegn.2008.02.002

Bernal, H., Shellman, J., \& Reid, K. (2004). Essential concepts in developing communityuniversity partnerships. Carelink: The partners in caring model. Public Health Nursing, 2l(1), 32-40. http://dx.doi.org/10.1111/j.1525-1446.2004.21105.x

Canadian Association of Schools of Nursing (2014). Entry-to-practice public health nursing competencies for undergraduate nursing education. Ottawa, ON: Author. Retrieved from: http://casn.ca/wpcontent/uploads/2014/12/FINALpublichealthcompeENforweb.pdf

Clarke, C., Gibb, C., \& Ramprogus, V. (2003). Clinical learning environments: An evaluation of an innovative role to support preregistration nursing placements. Learning in Health and Social Care, 2(2), 105-115. http://dx.doi.org/10.1046/j.1473-6861.2003.00044.x

Cohen, B., \& Gregory, D. (2009) Community health clinical education in Canada: Part 1- "state of the art". International Journal of Nursing Education Scholarship, 6(1) 1-17. http://dx.doi.org/10.2202/1548-923x.1637

Cooper, H., \& Geyer, R. (2008). Using 'complexity' for improving educational research in health care. Social Science \& Medicine, 67(1), 177-182. http://dx.doi.org/10.1016/j.socscimed.2008.03.041

Fraser, S. W., \& Greenhalgh, T. (2001). Coping with complexity: Educating for capability. British Medical Journal, 323(7316), 799-803. http://dx.doi.org/10.1136/bmj.323.7316.799

Ganley, B., Sheets, I., Buccheri, R., Thomas, S. A., Doerr-Kashani, P., Bolla, C., ... West, D. (2004). Collaboration versus competition: Results of an academic practice alliance. Journal of Community Health Nursing, 21(3), 153-165. http://dx.doi.org/10.1207/s15327655jchn2103_3

Gaberson, K. B., Oermann, M. H., \& Shellenbarger, T. (2015). Clinical teaching strategies in nursing. New York, NY: Springer Publishing Company.

Halcomb, E. J., Peters, K., \& McInnes, S. (2012). Practice nurses experiences of mentoring undergraduate nursing students in Australian general practice. Nurse Education Today, 32, 524-528. http://dx.doi.org/10.1016/j.nedt.2011.08.012

Hall, W. (2006). Developing clinical placements in times of scarcity. Nurse Education Today, 26, 627-633. http://dx.doi.org/10.1016/j.nedt.2006.07.009

Henderson, A., Heel, A., \& Twentyman, M. (2007). Enabling student placement through strategic partnerships between a health-care organization and tertiary institutions. Journal of Nursing Management, 15, 91-96. http://dx.doi.org/10.1111/j.1365-2934.2006.00634.x

Hoe Harwood, C, Reimer-Kirkham, S, Sawatzky, R, Terblanche, L., \& Van Hofwegen, L. (2009). Innovation in community clinical placements: A Canadian survey. International Journal of Nursing Education Scholarship, 6(1), Article 28.

http://dx.doi.org/10.2202/1548-923x.1860 
Hogard, E., Ellis, R., Ellis, J., \& Barker, C. (2005). Using a communication audit to improve communication on clinical placement in pre-registration nursing. Nurse Education Today, 25, 119-125. http://dx.doi.org/10.1016/j.nedt.2004.10.006

Hood, K., Leech, M., Cant, R., Gilbee, A., \& Baulch, J. (2014). Transforming nursing education: Development and evaluation of interprofessional clinical skills training for students on clinical placement. Journal of Nursing Education and Practice, 4(8), 97. http://dx.doi.org/10.5430/jnep.v4n8p97

Keller, L. O., Schaffer, M. A., Schoon, P. M., Brueshoff, B., \& Jost, R. (2011). Finding common ground in public health nursing education and practice. Public Health Nursing, 28(3), 261-270. http://dx.doi.org/10.1111/j.1525-1446.2010.00905.x

Kenyon, L., \& Peckover, S. (2008). 'A juggling act': An analysis of the impact of providing clinical placements for pre-registration students on the organization of community nursing and health visiting work. Nurse Education Today, 28, 202-209. http://dx.doi.org/10.1016/j.nedt.2007.03.014

Leurer, M. A., Meagher-Stewart, D., Cohen, B. E., Seaman, P. M., Buhler, S., Granger, M., \& Pattullo, H. (2011). Developing guidelines for quality community health nursing clinical placements for baccalaureate nursing students. International Journal of Nursing Education Scholarship, 8(1), 1-13. http://dx.doi.org/10.2202/1548-923x.2297

Murray, S., \& Williamson, G. (2009). Managing capacity issues in clinical placements for preregistration nurses. Journal of Clinical Nursing, 18, 3146-3154. http://dx.doi.org/10.1111/j.1365-2702.2008.02693.x

Peters, K., Halcomb, E. J., \& McInnes, S. (2013). Clinical placements in general practice: Relationships between practice nurses and tertiary institutions. Nurse Education in Practice, 186-191. http://dx.doi.org/10.1016/j.nepr.2012.09.007

Pesut, B., McLean, T., Reimer-Kirkham, S., Hartrick-Doane, G., Hutchings, D., \& Russell, L. B. (2015). Educating registered nursing and healthcare assistant students in communitybased supportive care of older adults: A mixed methods study. Nurse Education Today, 35(9), e90-e96. http://dx.doi.org/10.1016/j.nedt.2015.07.015

Pijl-Zieber, E. M. (2015) Community healthy nursing rhetoric: Our daily bread or pie-in-thesky? Journal of Nursing Heterodoxy, 1(2), 1-5.

Pijl-Zieber, E. M., Barton, S., Awosoga, O., \& Konkin, J. (2015). Disconnects in pedagogy and practice in community health nursing clinical experiences: Qualitative findings of a mixed method study. Nurse Education Today, 35(10), e43-e48. http://dx.doi.org/10.1016/j.nedt.2015.08.012

Pijl-Zieber, E. M., \& Kalischuk, R. G. (2011). Community health nursing practice education: Preparing the next generation. International Journal of Nursing Education Scholarship, 8(1), 1-13. http://dx.doi.org/10.2202/1548-923x.2250

Plowfield, L., Wheeler, E., \& Raymond, J. (2005). Time, tact, talent, and trust: Essential ingredients of effective academic-community partnerships. Nursing Education Perspectives, 26(4), 217-220. 
Reimer-Kirkham, S., Van Hofwegen, L., \& Pankratz, D. (2009). Keeping the vision: Sustaining social consciousness with nursing students following international learning experiences. International Journal of Nursing Education Scholarship, 6(1), Article 3. http://dx.doi.org/10.2202/1548-923x.1635

Reimer-Kirkham, S., Van Hofwegen, L., \& Hoe Harwood, C. (2005). Narratives of social justice: Learning in innovative clinical settings. International Journal of Nursing Education Scholarship, 2(1), Article 28. http://dx.doi.org/10.2202/1548-923x.1166

Rosenau, P., Watson, L., Vye-Rogers, L., \& Dobbs, M. (2015). Educating for complexity in nursing practice: A baccalaureate curriculum innovation. Quality Advancement in Nursing Education-Avancées en formation infirmière, 1(3), 4. http://dx.doi.org/10.17483/2368-6669.1039

Sloan, E., Keely, K., \& Groves, S. (2008). Challenges and benefits of international clinical placements in public health nursing. Nurse Educator, 33(1), 35. http://dx.doi.org/10.1097/01.nne.0000299493.00249.2d

Stallwood, L. G., \& Groh, C. J. (2011). Service-learning in the Nursing Curriculum: Are we at the level of evidence-based practice? Nursing Education Perspectives, 32(5), 400-405. http://dx.doi.org/10.5480/1536-5026-32.5.297

Stewart, W. (2007). Exploring learning opportunities for nursing students in prison settings. Nursing Standard, 22(2), 41-42. http://dx.doi.org/10.7748/ns2007.09.22.2.40.c4616

Van Doren, E. S., \& Vander Werf, M. (2012). Developing nontraditional community health placements. Journal of Nursing Education, 51(1), 46-49. http://dx.doi.org/10.3928/01484834-20111116-04

Wolff, A., Pesut, B., \& Regan, S. (2010). New graduate nurse practice readiness: Perspectives on the context shaping our understanding and expectations. Nurse Education Today, 30, 187-191. http://dx.doi.org/10.1016/j.nedt.2009.07.011 